\title{
Yellow Reaction Products from Tocopherols and Trimethylamine Oxide
}

\author{
Yukihiro IsHIKAwA \\ Hiroshima Food Research Institute, Hiroshima 730 \\ Received August 12, 1974
}

\begin{abstract}
Characteristic yellow substances obtained when tocopherols were treated with trimethylamine oxide under a nitrogen stream at $180^{\circ} \mathrm{C}$ were purified by means of silicagel column chromatography and preparative TLC. Their structures were determined by spectroscopic studies.

Treatment of $\alpha$-tocopherol with trimethylamine oxide gave 7-formyl- $\beta$-tocopherol, 5formyl- $\gamma$-tocopherol-3-en and 5-formyl- $\gamma$-tocopherol. Yellow reaction products from $\gamma$ - and $\delta$-tocopherols with trimethylamine oxide were 5-formyl- $\gamma$-tocopherol and 5-formyl- $\delta$-tocopherol, respectively.
\end{abstract}

Many studies have been done on the oxidation products obtained from reactions between tocopherols (Toc) and various oxidizing agents $^{1 \sim 9}$ including oxygen. ${ }^{10}$ However, the reaction products between Toc and materials having synergistic effects on Toc have never been investigated from the viewpoint of synergism.

During the investigations on the reactions between $\alpha-, \gamma-$, and $\delta$-Toc and trimethylamine oxide (TMAO), one of synergists for Toc, characteristic yellow spots were observed on thin-layer chromatograms and their structures were determined.

A mixture of $\alpha$-Toc and TMAO in liquid paraffin was treated under a nitrogen stream at $180^{\circ} \mathrm{C}$ for $2 \mathrm{hr}$ and a yellow substance was obtained by means of silicagel column chromatography and preparative TLC (benzene). On TLC with a solvent system, $n$-hexane-ether $(9: 1)$, this substance separated into the three yellow spots, $R f$ values of which were 0.74 , 0.66 and 0.59 for products A, B and C, respectively.

In the IR spectra of these products no absorption band near $3600 \mathrm{~cm}^{-1}$ due to an $\mathrm{OH}$ group was observed, whereas in the NMR spectra a peak due to an $\mathrm{OH}$ group was present near $12 \mathrm{ppm}$ as shown in Fig. 1. The IR spectra exhibited a strong absorption band near

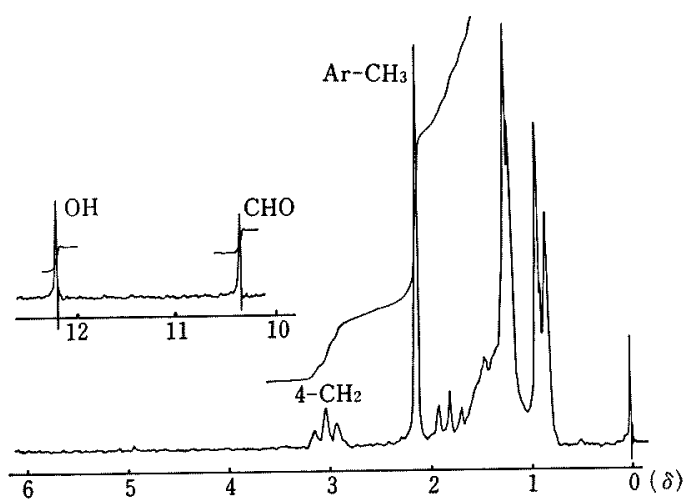

FIG. 1. NMR Spectrum of Product C $\left(\mathrm{CCl}_{4}, 60\right.$ $\mathrm{MHz}$.

$1630 \mathrm{~cm}^{-1}$ These facts indicate that the $\mathrm{OH}$ group is tightly bonded with an ortho functional group, that is with a CHO group at the 5- or 7-position in a chroman ring. As for aromatic methyl protons, product $\mathrm{A}$ has two signals at 2.17 and $2.42 \mathrm{ppm}$, but products $\mathrm{B}$ and $C$ have singlet signals at 2.22 and $2.17 \mathrm{ppm}$, respectively. Therefore, the $\mathrm{CHO}$ group in the chroman ring was found to exist at the 7position for product $A$ and at the 5-position for products B and C. In the NMR data of product $\mathrm{B}$ the appearance of signals of $\mathrm{CH}$ protons at 6.95 and $5.84 \mathrm{ppm}$ and their observed coupling constants $(10.0 \mathrm{~Hz})$ indicate the presence of a double bond between the 3- and 
<smiles>[R]C1(C)CCc2c(C)c(O)c(C=O)c(C)c2O1</smiles>

A<smiles>[R]C1(C)CCc2c(O)c(C)c(O)c(C)c2O1</smiles>

C, D<smiles>[R]C1C=Cc2c(C=O)c(O)c(C)c(C)c2O1</smiles>

B<smiles>[R]C1(C)CCc2c(C=O)c(O)cc(C)c2O1</smiles>

E
$\mathrm{R}: \mathrm{C}_{16} \mathrm{H}_{33}$

Fig. 2. Structure of Products $A \sim E$.

\section{4-positions in the chroman ring.}

From the results obtained above, the structures of products $\mathrm{A}, \mathrm{B}$ and $\mathrm{C}$ derived from $\alpha$-Toc with TMAO were determined to be 7formyl- $\beta$-Toc, 5-formyl- $\gamma$-Toc-3-en and 5formyl- $\gamma$-Toc, respectively, as shown in Fig. 2.

Kohl et $a l .{ }^{11)}$ reported on plastochromenol-8 (solanochromene) as a substance having a double bond between the 3- and 4-positions, but such a substance has never been obtained in the case of Toc.

On the reaction of $\gamma$ - and $\delta$-Toc with TMAO, yellow substances, product D from $\gamma$-Toc and product $\mathrm{E}$ from $\delta$-Toc, were obtained. Product $\mathrm{D}$ was found to be identical with product $\mathrm{C}$ when their spectral and chromatographic data were compared.

Product $\mathrm{E}$ has two possible structures, that is 5- or 7-formyl- $\delta$-Toc. In the NMR spectrum the appearance of two protons triplet, assigned to the 4-position $\mathrm{CH}_{2}$ protons, at lower field (3.02 ppm) is thought to be due to the effect of a CHO group at the 5-position in comparison with the data of product $\mathrm{A}$ and $\mathrm{C}$.

Nilsson et al. ${ }^{12)}$ reported that a very strong preference existed for reaction at the 5-position versus the 7-position of Toc as a result of the directing effect of the heterocyclic ring.

The structure of product $E$ from $\delta$-Toc with TMAO, therefore, was determined to be 5formyl- $\delta$-Toc as seen in Fig. 2.

It is of interest for us that the treatment of each Toc with TMAO gives 5-formyl derivatives regardless of whether the substituent in the 5-position is hydrogen or methyl. Skinner and Parkhurst, ${ }^{4}$ and Fujimaki et al. ${ }^{10)}$ reported on a 5-formyl derivative of $\alpha$-Toc model compound (a phytyl group at the 2-position in a chroman ring is replaced with a methyl group), but the formyl derivatives of various Toc themselves have never been obtained.

\section{EXPERIMENTAL}

NMR spectra were recorded in deuteriochloroform and carbon tetrachloride on JEOL JNM-PS-100 (100 $\mathrm{MHz}$ ) and Hitachi R-24 (60 MHz) NMR spectrometers, respectively. Mass spectrometry was carried out on JEOL JMS-01-SG and Hitachi RMU-6L mass spectrometers by a direct sample introducing method. Gas chromatographic analyses were carried out with a Schimadzu GC-5A gas chromatograph under the following conditions; Column: glass column $(0.3 \times 200$ $\mathrm{cm})$ packed with silicon GE-SE $30(1.5 \%)$ on Chromosorb W, Detector: HFID, Column temperature: $235^{\circ} \mathrm{C}$. Thin-layer plates (thickness, $0.5 \mathrm{~mm}$ ) were prepared with Kieselgel $\mathrm{G}$ and $\mathrm{HF}_{254}$ (Merck), and the chromatograms were detected with ultraviolet light and the Emmerie-Engel reagent.

$d l-\alpha-(100 \%), d-\gamma-(77 \%)$, and $d-\delta$-Toc $(98 \%)$ were kindly presented by Eisai Co.

\section{Isolation of products $A, B$ and $C$}

A mixture of $\alpha$-Toc $(1 \mathrm{~g})$ and TMAO $(500 \mathrm{mg})$ in liquid paraffin $(8 \mathrm{ml})$ was treated under a nitrogen stream at $180^{\circ} \mathrm{C}$ for $2 \mathrm{hr}$, dissolved in $n$-hexane and then applied on a column of silicagel (Kanto Chemical Co.) equilibrated with $n$-hexane. After the liquid paraffin was washed away with $n$-hexane, eluent with an increasing ratio of benzene to $n$-hexane gave a yellow spot ( $R f$ 0.75) on TLC by using benzene as a solvent. Fractions containing this material were combined and then applied to the thin-layer plates for purification. The development was carried out with a solvent system: $n$-hexane-ether $(9: 1)$. The three yellow bands, $R f$ values of which were $0.74,0.66$ and 0.59 for products A, B and C, respectively, were removed from the plates.

The properties of each product are as follows: Product A, MS $m / e: 444\left(M^{+}\right), 219,217,179$. IR $\nu_{\max }^{\mathrm{CCl}}$ $\mathrm{cm}^{-1}: 1635(\mathrm{C}=\mathrm{O})$. UV $\lambda_{\max }^{\mathrm{EtOH}} \mathrm{nm}(\varepsilon): 241,283(10670)$ 395 (2870). NMR $\left(\mathrm{CDCl}_{3}\right) \delta: 11.90(1 \mathrm{H}, \mathrm{OH}), 10.40$ (1H, CHO), $2.70\left(2 \mathrm{H}, 4-\mathrm{CH}_{2}\right), 2.42\left(3 \mathrm{H}, \mathrm{CH}_{3}\right), 2.17$ $\left(3 \mathrm{H}, \mathrm{CH}_{3}\right), 1.84\left(2 \mathrm{H}, 3-\mathrm{CH}_{2}\right)$. GLC $\left(t_{R}\right): 45.1 \mathrm{~min}$ $(\alpha-T o c, 31.5 \mathrm{~min}) . \quad$ TLC $(R f): 0.19$ ( $n$-hexane-chloroform $=2: 1)$. Yield: $17 \mathrm{mg}$. Product $B$, MS $m / e$ : $442\left(\mathrm{M}^{+}\right), 427,217,189,159$. IR $\nu_{\max }^{\mathrm{CCl}_{4}} \mathrm{~cm}^{-1}: 1638$ $(\mathrm{C}=\mathrm{O})$. UV $\lambda_{\max }^{\mathrm{EtOH}} \mathrm{nm}(\varepsilon): 243,249,289 \sim 296$ (broad, 
11560), $412(3720) . \quad \mathrm{NMR}\left(\mathrm{CDCl}_{3}\right) \delta: 12.07(1 \mathrm{H}, \mathrm{OH})$ $10.40(1 \mathrm{H}, \mathrm{CHO}), 6.95(1 \mathrm{H}, \mathrm{d}, 4-\mathrm{CH}, J=10.0 \mathrm{~Hz})$, $5.84(1 \mathrm{H}, \mathrm{d}, 3-\mathrm{CH}, J=10.0 \mathrm{~Hz}), 2.22\left(6 \mathrm{H}, 2 \mathrm{CH}_{3}\right)$. GLC $\left(t_{R}\right): 34.8 \mathrm{~min}$. TLC $(R f): 0.23$. Yield: $16 \mathrm{mg}$. Product C, MS m/e: $444\left(\mathrm{M}^{+}\right), 220,217,179$. IR $\nu_{\max }^{\mathrm{CCl}_{4}} \mathrm{~cm}^{-1}: 1630(\mathrm{C}=\mathrm{O})$. UV $\lambda_{\max }^{\mathrm{EtOH}} \mathrm{nm}(\varepsilon): 239,287$ (13610), 391 (4200). NMR $\left(\mathrm{CDCl}_{3}\right) \delta: 12.20(1 \mathrm{H}, \mathrm{OH})$, $10.32(1 \mathrm{H}, \mathrm{CHO}), 3.04\left(2 \mathrm{H}, 4-\mathrm{CH}_{2}\right), 2.17\left(6 \mathrm{H}, 2 \mathrm{CH}_{3}\right)$, $1.84\left(2 \mathrm{H}, 3-\mathrm{CH}_{2}\right)$. GLC $\left(t_{R}\right): 44.0 \mathrm{~min}$. TLC $(R f)$ : 0.25 . Yield: $120 \mathrm{mg}$.

\section{Isolation of product $D$}

$\gamma$-Toc (ca. $77 \%$ in purity) was purified by repeating preparative TLC. A mixture of $\gamma$-Toc $(800 \mathrm{mg})$ and TMAO $(400 \mathrm{mg})$ in liquid paraffin $(6 \mathrm{ml})$ was treated under a nitrogen stream at $180^{\circ} \mathrm{C}$ for $1 \mathrm{hr}$. On TLC (benzene) a yellow substance $(R f 0.75)$ was obtained and this gave a single spot ( $R f 0.59)$ when TLC was carried out with a $n$-hexane-ether $(9: 1)$ solvent system.

The properties of product D are the same as those of product C. Yield: $60 \mathrm{mg}$.

\section{Isolation of product $E$}

$\delta$-Toc $(710 \mathrm{mg})$ was treated with TMAO $(355 \mathrm{mg})$ under the same conditions as in product $D$. A yellow spot ( $R f 0.68$ ) on TLC (benzene) was collected.

The analytical data of product $E$ are as follows: MS m/e: $430\left(\mathrm{M}^{+}\right), 412,264,219,205,149$. IR $\nu_{\max }^{\mathrm{CCl}_{4}} \mathrm{~cm}^{-1}: 1640(\mathrm{C}=\mathrm{O})$. UV $\lambda_{\max }^{\mathrm{EtOH}} \mathrm{nm}(\varepsilon): 241,279$ (10290), 382 (3570). NMR $\left(\mathrm{CCl}_{4}\right) \delta: 10.48(1 \mathrm{H}, \mathrm{OH})$, $10.13(1 \mathrm{H}, \mathrm{CHO}), 6.55(1 \mathrm{H}, \mathrm{Ar}-\mathrm{H}), 3.02\left(2 \mathrm{H}, 4-\mathrm{CH}_{2}\right)$, $2.16\left(3 \mathrm{H}, \mathrm{CH}_{3}\right), 1.80\left(2 \mathrm{H}, 3-\mathrm{CH}_{2}\right)$. GLC $\left(t_{R}\right): 38.5 \mathrm{~min}$ $(\delta$-Toc, $21.5 \mathrm{~min})$. TLC $(R f): 0.85$ (chloroform). Yield: $28 \mathrm{mg}$.

Acknowledgement. The author wishes to express his sincere thanks to Dr. M. Fujimaki, Tokyo Univer- sity, for much useful advice and Dr. E. Yuki, of this Institute, for his encouragement throughout this work. The author is also indebted to Mr. K. Yamanaka, Industrial Research Institute of Hyogo Prefecture, and Eisai Co. for measuring mass spectra. This study was supported by a grant from Shin-Shokuhin Kenkyu Kyogikai.

\section{REFERENCES}

1) D. R. Nelan and C. D. Robeson, J. Am. Chem. Soc., 84, 2963 (1962).

2) D. McHale and J. Green, Chem. Ind., 1963, 982; idem, ibid., 1964, 366.

3) W. A. Skinner and R. M. Parkhurst, J. Org. Chem., 29, 3601 (1964).

4) W. A. Skinner and R. M. Rarkhurst, ibid., 31, 1248 (1966).

5) W. A. Skinner and P. Alaupovic, ibid., 28, 2854 (1963).

6) M. Komoda, N. Onuki and I. Harada, Agr. Biol. Chem., 31, 461 (1967).

7) M. Komoda and I. Harada, J. Am. Oil Chem. Soc., 46, 18 (1969).

8) J. L. G. Nilsson, Acta Pharm. Suecica, 6, 1 (1969).

9) L. Telegdy-Kovats and E. Berndorfer-Kraszner, Period. Polytech. Chem. Eng., 15, 23 (1971).

10) M. Fujimaki, K. Kanamaru, T. Kurata and $O$. Igarashi, Agr. Biol. Chem., 34, 1781 (1970).

11) D. H. Kohl, P. M. Wood, M. Weissman and J. R. Wright, Magn. Resonances Biol. Res., Rep. Int. Conf., ed. by Franconi, Cafiero; Gordon and Breach, New York, 1969, p. 189.

12) J. L. G. Nilsson, G. D. Daves, Jr. and K. Folkers, Acta Chem. Scand., 22, 207 (1968); J. L. G. Nilsson, H. Sievertsson and H. Selander, ibid., 23, 859 (1969). 